\title{
The effects of septal lesion on the open-field social behavior of Sprague-Dawley albino rats
}

\author{
DAVID A. JOHNSON, CHIANG-HUA CHANG, \\ BRETT E. POLENCHAR, and MICHAEL M. PATTERSON \\ Ohio University, Athens, Ohio
}

\begin{abstract}
Open-field contact time was observed in Holtzman albino rats pre- and postoperatively. Although social contact was quite variable within pairs, postoperatively there was still a marked increase in social cohesiveness across days. These results are similar but not identical to results observed in prior studies using Long-Evans hooded rats.
\end{abstract}

Previous studies in our laboratory (Johnson, Spiker \& Carlson, 1984; Poplawsky \& Johnson, 1973) as well as a number of studies at Ohio State (Jonason \& Enloe, 1971; Meyer, Ruth, \& Lavond, 1978), have demonstrated that lesions of the septal forebrain in Long-Evans hooded rats result in a marked increase in open-field gregariousness (contact time). Increased contact time has also been observed in adult animals following septal lesions produced in 7-day-old infant Long-Evans rats (Johnson, 1972).

In our laboratory, we have recently begun to investigate the effects of septal damage produced by neurotoxic chemicals (kainic acid and AF64A). For the biochemical work, we found that Sprague-Dawley albino rats had frequently been used as subjects. Before we began this series of studies, we were interested in determining whether the effects of electrolytic septal lesions in albino adult rats on open-field social behavior were comparable to the effects typically found in Long-Evans-strain animals. Such a similarity of effect could not be readily assumed across strains. Numerous strain differences in open-field activity have been documented between inbred strains of lab mice (Crusio, Kerbusch, \& von Abeelen, 1984).

\section{METHOD}

The design of the present study was similar to that reported by Jonason and Enloe (1971) and Poplawsky and Johnson (1973). Twenty male Sprague-Dawley albino rats were received in the lab at 70 days of age. All animals were housed in standard individual rack cages until 90 days of age. At that time, preoperative observation was begun. On Days 1 and 2 of observation, the animals were placed singly in the Latane open field for a 5-min period of adaptation. On Days 3-12, we marked the paired animals and recorded social contact time. After the 10th day of preoperative contact-time data had been recorded, all animals received bilateral electrolytic septal lesions. After surgery, the animals were returned to their individual cages for a 21-day recovery period. Contact time

This research was supported by a grant from the Ohio University Research Foundation to D. A. Johnson. All the authors are with the Department of Psychology, and B. Polenchar and M. Patterson are also with the College of Osteopathic Medicine, Ohio University, Athens, OH 45701. for 10 daily, 5 -min, postoperative sessions was recorded after the recovery period. All animals were then anesthetized and perfused intracardially, and their brains were removed for histology.

Procedures used to record contact time were the same as those reported by Jonason and Enloe (1971) and were essentially the same as those used in all the above studies, except that Poplawsky and Johnson (1973) used 15-min instead of 5-min observation periods. Both pair members were placed in the Latane openfield, and cumulative time spent in any physical contact during the 5-min observation period was recorded.

Septal lesions were produced under phenobarbital anesthesia (dosage of $1 \mathrm{mg} / \mathrm{kg}$ body weight). All animals were also given $1 \mathrm{mg}$ atropine sulfate to prevent congestion. The Kopf stereotaxic device had the mouth bar elevated $5 \mathrm{~mm}$. After the incision, a trephine hole in the skull was produced $7.8 \mathrm{~mm}$ anterior to interaural zero. A stainless steel electrode, insulated except for $.5 \mathrm{~mm}$ at the tip, was lowered at point $+7.8 \mathrm{~mm}$ anterior and $\pm .5 \mathrm{~mm}$ lateral to stereotaxic zero. The electrode was lowered to a depth of $5 \mathrm{~mm}$ below the dura. A dc current of $2.0 \mathrm{~mA}$ was passed for $20 \mathrm{sec}$ on each side of the septum.

After behavioral observation had been completed all animals were perfused intracardially with physiological saline followed by $10 \%$ Formalin. Frozen sections were collected throughout the lesions, and these were stained with cresyl violet to verify the location and extent of the lesions.

\section{RESULTS AND DISCUSSION}

Septal lesions were judged to be satisfactory, although they were not quite as large as in the studies cited above. The dorsal septum was destroyed in all the subjects. There was some variability in the ventrolateral extent of the lesions. Lesions began posterior to the genu of the corpus callosum and spread posteriorly into the fornix. There was no damage to the hippocampus. There was a variable degree of sparing observed in ventrolateral septal areas. The medial septum was destroyed in all animals.

Contact-time data from the current study, as well as similar data from prior studies using Long-Evans strain rats, are presented in Figure 1. We found a significant postoperative increase in contact time as a function of septal lesions $[F(1,14)=13.8, p<.01]$. In comparing our results with results from studies using Long-Evans-strain rats, it is apparent that the postoperative increase in social contact in the current study was more gradual in onset. It would also appear that the increased contact time 


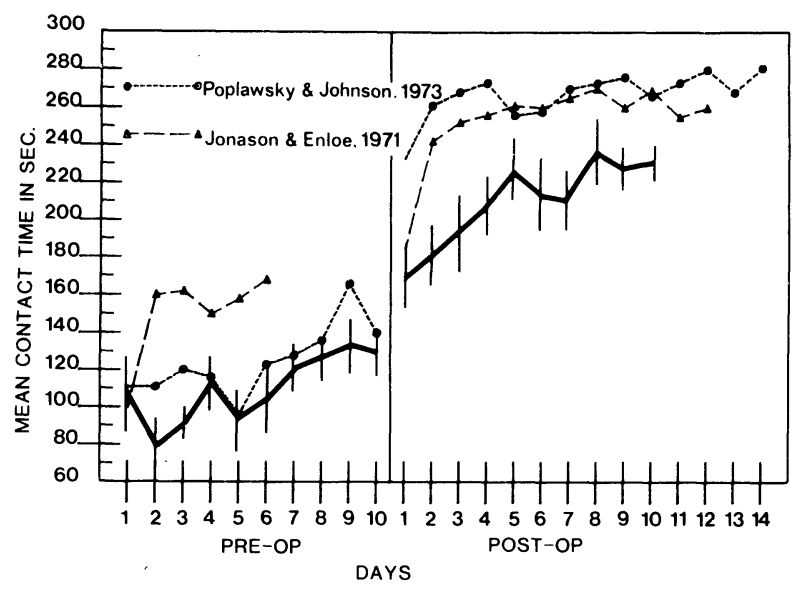

Figure 1. Mean number of seconds spent in contact by pairs of rats pre- and postoperatively: A comparison of results from the current and previous studies. Results from the present study include standard error lines.

in the current study following septal lesions in SpragueDawley albino rats is, although statistically significant, not quite as large as has been observed in prior studies using hooded rats. The heightened gregariousness effect in albino rats, then, seems to require a longer period of postoperative observation to stabilize. The slightly lower levels of contact time in our albinos even after stabilization of contact time may reflect a degree of strain difference in the magnitude of the effect of septal lesion on social contact time. It is also possible that differences in the completeness of septal lesions between studies may account for this difference (there was more sparing of septal tissue in the current study).
In summary, the effects of septal lesions on the openfield social behavior of Sprague-Dawley albino rats in the current study were similar, but not identical, to the effects found in prior studies using hooded rats. Our data suggest that, in further studies using albino animals, it would be advantageous to collect postoperative data for at least 15 and perhaps 20 days. This would allow time to observe the full effect of the lesion beyond the first 5-7 days of stabilization. It may also be advantageous to analyze postoperative data after stabilization of behavior has resulted. For statistical analysis, perhaps the first 57 days should be treated as a period of adaptation.

\section{REFERENCES}

Crusio, W. E., Kerbusch, M. L., von Abeelen, T. H. F. (1984). The replicated diallel cross: A generalized method of analysis. Behavior Genetics, 14, 81-104.

JoHNSON; D. A. (1972). Developmental aspects of recovery of function following septal lesions in the infant rat. Journal of Comparative and Physiological Psychology, 78, 331-348.

Johnson, D. A., SPIKer, M., \& CARLson, K. (1984). Open-field social behavior in rats as a function of septal lesions in infancy and group vs. isolated rearing conditions. Physiological Psychology, 12, 14-16.

JoNASON, K. R., \& ENLOE, L. J. (1971). Alterations in social behavior following septal and amygdaloid lesions in the rat. Journal of Comparative and Physiological Psychology, 75, 286-301.

Meyer, D. R., Ruth, R. A., \& Lavond, D. G. (1978). The septal social cohesiveness effects: Its robustness and main determinants. Physiology \& Behavior, 21, 1027-1029.

PoplawSKY, A., \& JoHNSON, D. A. (1973). Open-field social behavior of rats following lateral or medial septal lesions. Physiology \& Behavior, 11, 845-854.

(Manuscript received for publication March 4, 1985.) 